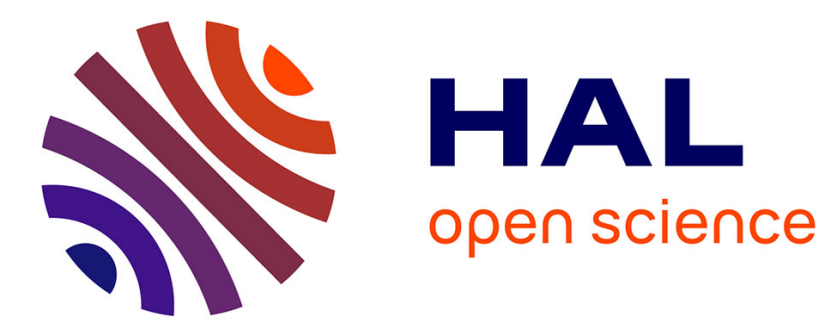

\title{
Lanthanidocenes: Synthesis, Structure, and Bonding of Linear Sandwich Complexes of Lanthanides
}

\author{
Mathieu Xemard, Sebastien Zimmer, Marie Cordier, Violaine Goudy, Louis
} Ricard, Carine Clavaguera, Grégory Nocton

\section{- To cite this version:}

Mathieu Xemard, Sebastien Zimmer, Marie Cordier, Violaine Goudy, Louis Ricard, et al.. Lanthanidocenes: Synthesis, Structure, and Bonding of Linear Sandwich Complexes of Lanthanides. Journal of the American Chemical Society, 2018, 140 (43), pp.14433-14439. hal-01999492

\section{HAL Id: hal-01999492 \\ https://hal.science/hal-01999492}

Submitted on 11 Nov 2020

HAL is a multi-disciplinary open access archive for the deposit and dissemination of scientific research documents, whether they are published or not. The documents may come from teaching and research institutions in France or abroad, or from public or private research centers.
L'archive ouverte pluridisciplinaire HAL, est destinée au dépôt et à la diffusion de documents scientifiques de niveau recherche, publiés ou non, émanant des établissements d'enseignement et de recherche français ou étrangers, des laboratoires publics ou privés. 


\title{
Lanthanidocenes: Synthesis, Structure and Bonding of Linear Sand- wich Complexes of Lanthanides
}

\author{
Mathieu Xémard, ${ }^{\dagger}$ Sébastien Zimmer, ${ }^{\dagger}$ Marie Cordier, ${ }^{\dagger}$ Violaine Goudy, ${ }^{\dagger}$ Louis Ricard, ${ }^{\dagger}$ Carine Clava- \\ guéra, ${ }^{\ddagger}$ and Grégory Nocton ${ }^{\dagger *}$ \\ ${ }^{\dagger}$ LCM, CNRS, Ecole polytechnique, Université Paris-Saclay, Route de Saclay, 91128 Palaiseau cedex, France. \\ ${ }^{\ddagger}$ Laboratoire de Chimie Physique, CNRS-Université Paris-Sud, Université Paris-Saclay, 15 avenue Jean Perrin, 91405 Orsay \\ Cedex, France.
}

ABSTRACT: The article presents the synthesis, structure, and bonding of a series of neutral and linear sandwich compounds with the cyclononatetraenyl (Cnt) ligand and divalent lanthanides. These compounds account for the emergence of the lanthanidocene series in reference to the ferrocene and uranocene. The synthetic strategy uses the solubility difference between two conformation isomers of the ligand as well as their isomerization induced by solvent coordination, yielding to the isomorphous and isostructural, neutral and rigorously linear sandwich complexes. The molecular structures highlight a Cnt-Ln-Cnt angle at $180^{\circ}$ and a ring size close to the Cnt-Cnt (centroid) distance. A qualitative molecular orbital diagram is provided in $\mathrm{D}_{9 \mathrm{~d}}$ symmetry and DFT calculations enforce the bonding model.

\section{INTRODUCTION.}

The initial report of a new type of organo-iron compound in $1951^{1}$ has marked the onset of an extensive and fruitful research field devoted to the synthesis and the structural analysis of the so-called metallocenes. ${ }^{2-3}$ The sandwich shape of these molecules is fascinating since it provides a great platform for further substitutions. Additionally, the high symmetry of such molecules is particularly interesting since it confers various reactivity and physical properties to the metal center, depending upon the electron count. ${ }^{4}$ Thus, not only that these compounds broke the fundamental nature of the structural perspectives of the time, but it also fed multiple research fields for more than 60 years.

The cyclopentadienyl (Cp) ligand (Chart 1) that is used for the synthesis of neutral metallocenes is small, Hückel aromatic, mono-anionic, and is therefore particularly well adapted for transition metals of the + II oxidation state. ${ }^{4}$ For the main group metallocenes, the lone-pair p orbital causes a bending in groups 14 and 15 complexes, ${ }^{5-6}$ while for larger elements with different oxidation states, such as the f-elements, the coordination chemistry studies with the $\mathrm{Cp}$ ligand have also led to other geometries than the linear sandwich one. ${ }^{7-9}$ Thus, Streitwieser proposed to use the cyclooctatetraenyl (Cot) ligand for 5f-elements of +IV oxidation state: in 1968, the synthesis ${ }^{10}$ and the structure ${ }^{11}$ of a neutral and linear sandwich complex of uranium was reported and named uranocene, in reference to ferrocene. ${ }^{2-3}$ For the 4 f-elements, the lanthanides, the only element for which the formal +IV oxidation state is well-known is $\mathrm{Ce}$ : cerocene, i.e. $\mathrm{Ce}(\mathrm{Cot})_{2}$, is the only one of the series that is reported yet, ${ }^{12}$ and the numerous reports on its bonding and on the formal oxidation state of cerium ${ }^{13-17}$ highlight the large fundamental interest for this type of molecules.
For the other lanthanides, three $\mathrm{Cp}$ ligands surround the metal center with +III oxidation states, leading to $\mathrm{Cp}_{3} \mathrm{Ln},{ }^{7-8}$ while with +II oxidation states, a bending is induced because of inter-molecular interactions. ${ }^{18-19}$ Furthermore, in Cot chemistry, the anionic nature of the trivalent metal complexes also generally results in a bending and/or in the formation of chain structures, preventing the establishment of a systematic isostructural series of linear sandwich complexes of lanthanides. $^{20-22}$

An interesting step toward such a series has been done with the report of formal zero-valent bis(arene) lanthanides compounds synthesized in the 1980's with the bulky 1,3,5-tristert-butylbenzene ligand. $^{23-24}$ Indeed, in order to reach the desired linear geometry, the preferred solution is to use large substituents, assuming that the sterics will dictate the symmetry. ${ }^{25-27}$ This strategy has proven to be useful in the synthesis of a series of cationic $\mathrm{Cp}_{2}{ }_{2} \mathrm{Ln}^{+}{ }^{28}$ in which the $\mathrm{Cp}_{2}{ }_{2} \mathrm{Dy}^{+}$ closely linear geometry allowed to breake records in single molecule magnets (SMM) properties, ${ }^{29-31}$ but also allowing spontaneous reduction of $\mathrm{Sm}^{\mathrm{III} 32}$ and extraordinary luminescence of $\mathrm{Eu}^{\text {II }}$ complexes. ${ }^{33}$

Chart 1. Aromatic ligands used for the design of sandwich complexes.

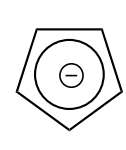

$\mathrm{Cp}^{-}$

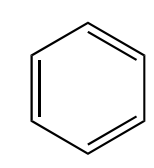

benzene

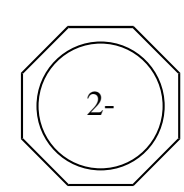

$\operatorname{Cot}^{2-}$

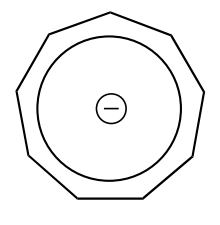

$\mathrm{Cnt}^{-}$
Our strategy is based on the use of divalent lanthanides, whose chemistry expended largely in the last decades, ${ }^{34-35}$ with the next Hückel-aromatic and monoanionic ligand after the $\mathrm{Cp}$ ligand, the cyclononatetraenyl anion $\left(\mathrm{Cnt}, \mathrm{C}_{9} \mathrm{H}_{9}{ }^{-}\right.$, Chart 
1). ${ }^{36-37}$ A recent article by Nakajima et al. reported the structural and physical properties of the $\mathrm{Eu}(\mathrm{Cnt})_{2}$ complex, ${ }^{38}$ while Walter et al. have reported the synthesis of the $\mathrm{Ba}(\mathrm{Cnt})_{2}$ complex. $^{39}$ In this article, we report the original synthesis, the structure and the bonding of several $\operatorname{Ln}(\mathrm{Cnt})_{2}$ complexes, a series of neutral and linear sandwich compounds of lanthanides, justifying the name of lanthanidocenes.

\section{RESULTS AND DISCUSSION.}

Synthesis and Structural Analysis. The KCnt salt has been prepared from a literature procedure, ${ }^{37,40}$ and can be recrystallized from diethylether, forming yellow X-ray suitable crystals (Figure 1). The structure shows a positional disorder for the $\mathrm{C} 1$ carbon atom, indicating the presence of two isomers: the cis,cis,cis,cis-cyclononatetraenyl $\left(\mathbf{L}_{1}-c i s\right)$, in which all carbon atoms form a regular ring and the cis,cis,cis,transcyclononatetraenyl ( $\mathbf{L}_{\mathbf{1}}$-trans), in which one carbon atom is moved inside the ring (Chart 2).

Chart 2. Structure of the two isomers of L1.

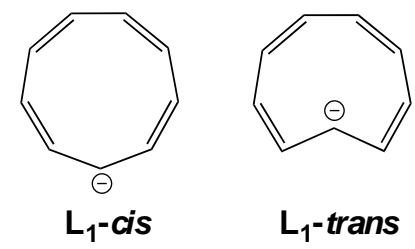

Both isomers are also present in solution (Figure $\mathrm{S} 1$ ): the ${ }^{1} \mathrm{H}$ NMR spectrum of the crystals in $\mathrm{CD}_{3} \mathrm{CN}$ shows the characteristic singlet at $6.94 \mathrm{ppm}$ of $\mathbf{L}_{\mathbf{1}^{-}}$cis as well as the characteristic triplet associated with the internal hydrogen atom $\left(\mathrm{L}_{1}\right.$-trans $)$ at $-3.54 \mathrm{ppm}$ in a 1:4 ratio. Boche et al. measured an activation free-enthalpy of $29.7 \mathrm{kcal}^{\mathrm{mol}}{ }^{-1}$ in thf at $60{ }^{\circ} \mathrm{C}$ for the $\mathrm{KCnt}$ isomerization process. ${ }^{41}$ Thus, if the ring opening reaction time is extended to 3 days instead of several hours, only the symmetrical isomer $\mathrm{L}_{1}$-cis is obtained. However, since the latter is not soluble in diethylether, its purification by crystallization is rendered very difficult.

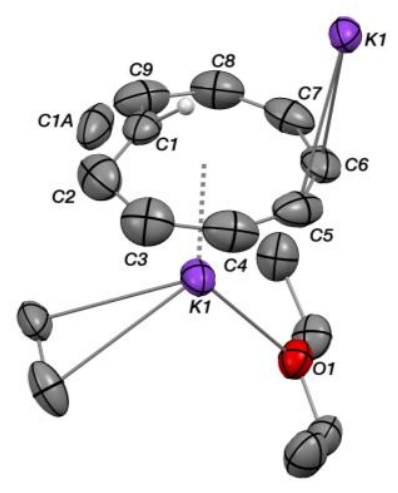

Figure 1. Molecular structure of $\mathrm{KL}_{\mathbf{1}} \cdot \mathrm{OEt}_{2}$ recorded at $150 \mathrm{~K}$; thermal ellipsoids are shown at $50 \%$ probability. $\mathrm{C} 1$ and $\mathrm{C} 1 \mathrm{~A}$ show the positional disorder. Hydrogen atoms have been removed for clarity except that of $\mathrm{C} 1$ in order to show its orientation.

Because of these solubility problems, the reaction of $\mathbf{L}_{\mathbf{1}}$-cis with lanthanide diiodide precursors leads, in very low yield $(1 \%-5 \%)$, to powders, which are not greatly soluble in hydrocarbon solvents. ${ }^{34}$ Therefore, the isomer mixture is preferred for the syntheses. When the synthesis is performed in diethylether from a suspension of $\mathrm{YbI}_{2}$ with 2 equivalents of the isomers mixture, the yield remains low (15\%). Performing the reaction in thf does not improve the yield since after evaporation of the solvent and extraction of the residue in toluene it still remains very similar. However, when the salt metathesis reaction is performed directly in toluene with a few drops of thf, the suspension turns immediately green and a good amount (43\%) of the crystals of, $\mathrm{Yb}(\mathrm{Cnt})_{2}, 1$ can be obtained, after filtration, from the green solution at $-35^{\circ} \mathrm{C}$.

The ${ }^{1} \mathrm{H}$ NMR spectrum shows three different complexes in solution: the two homoleptic $\mathrm{Yb}\left(\mathbf{L}_{\mathbf{1}} \text {-cis }\right)_{2},\left(\mathbf{1}^{c c}\right) \mathrm{Yb}\left(\mathbf{L}_{\mathbf{1}} \text {-trans }\right)_{2}$ $\left(\mathbf{1}^{t t}\right)$ complexes and the heteroleptic $\operatorname{Yb}\left(\mathbf{L}_{1}\right.$-cis $)\left(\mathbf{L}_{\mathbf{1}}\right.$-trans $)\left(\mathbf{1}^{c t}\right)$ complex (Figure S2). The characteristic singlet of $1^{c c}$ at 7.16 ppm and both characteristic triplets of $1^{c t}$ and $1^{t t}$ at $-3.97(J=$ $15.4 \mathrm{~Hz})$ and $-4.13 \mathrm{ppm}(J=15.5 \mathrm{~Hz})$ allow their identification. The ${ }^{13} \mathrm{C}$ NMR shows only 6 resonances for the two major isomers, one for $1^{c c}$, and 5 for $1^{t t}$. Among them, 5 resonances have ${ }^{1} J_{\mathrm{CH}}$ coupling constants in a $154-162 \mathrm{~Hz}$ range, in good agreement with $\mathrm{sp}^{2}$ aromatic carbon atoms, while the last one has a ${ }^{1} J_{\mathrm{CH}}$ of $126 \mathrm{~Hz}$, in agreement with an $\mathrm{sp}^{3}$ carbon atom (Figure S3-S4) and can be attributed to the carbon away from the ring plane.

A similar synthetic procedure than that of 1 was used to afford $\mathrm{Sm}(\mathrm{Cnt})_{2}$ (2) in better yields $(56 \%)$ as brown crystals (Scheme 1). The ${ }^{1} \mathrm{H}$ NMR shows 12 resonances (three isomers) spanning from 50.3 to $-2.35 \mathrm{ppm}$ (Figure S8). All of them can be all identified with a 2D-COSY experiment (Figure S9). The isomerization must be performed at temperatures close to room temperature $\left(25^{\circ} \mathrm{C}\right)$ to be optimum since the rate of the reaction slows down when increasing the temperature, preventing to realize an Eyring analysis. ${ }^{37}$ After several days, the crystallization of yellow $\left(1^{\mathbf{c c}}\right)$ and orange $\left(2^{\mathbf{c c}}\right)$ crystals occurs in unsatisfactory low yields, ${ }^{38}$ which encouraged us to search for better isomerization solvents.

Scheme 1. Synthetic scheme for 1, 3 and 4.

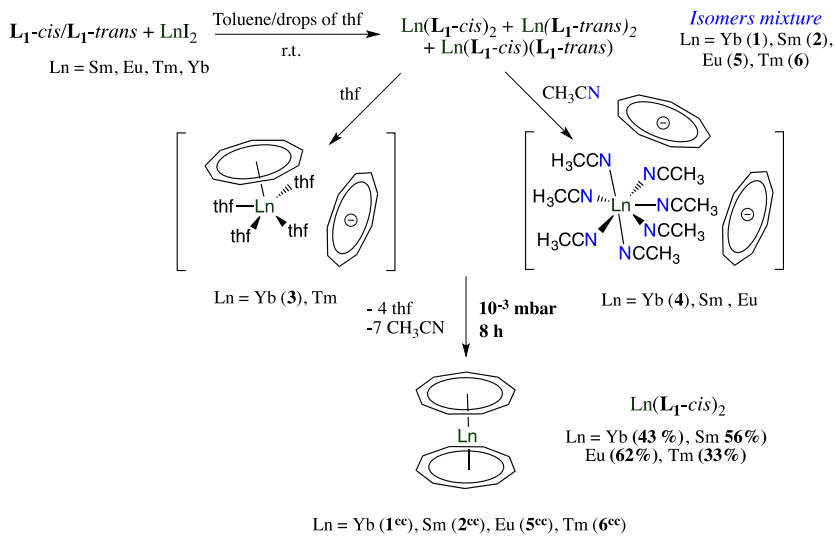

When crystals of 1 are dissolved in thf, red crystals crashed out immediately while the dilute ${ }^{1} \mathrm{H}$ NMR shows only one broad singlet at $6.92 \mathrm{ppm}$ (Figure S5). The X-ray diffraction analysis of the crystals shows an ion-pair of $\left[\mathrm{Yb}\left(\mathbf{L}_{1}\right)(\text { thf })_{4}\right]\left[\mathrm{L}_{1}\right]$ (3) with one Cnt ligand coordinated to the ytterbium metal while the second one is not (Figure 2). Four molecules of thf complete the coordination sphere of ytterbium, viz. thf is a good donor for lanthanide ions and competes with the Cnt coordination. The $\mathrm{Yb}-\mathrm{O}$ average distance is 2.44(3) $\AA$ (Figure 2 and Table S11), in agreement with a divalent metal center. ${ }^{42}$ The Cnt ligand coordinated to the ytterbium also exhibits a disorder between the cis and trans form in a 1:1 ratio. Howev- 
er, the outer-sphere ligand shows only the cis form, which means that it has been entirely isomerized. The broad and unique resonance in ${ }^{1} \mathrm{H}$ NMR at $6.92 \mathrm{ppm}$ accounts for a possible exchange between both ligands. This behavior is very interesting since it means that the isomerization barrier is related to the coordination to a given metal center. ${ }^{41}$ Since a fast isomerization process would be very advantageous for the synthesis of $\mathbf{1}^{c c}$ and $\mathbf{2}^{c c}$, we turned to acetonitrile as a solvent.
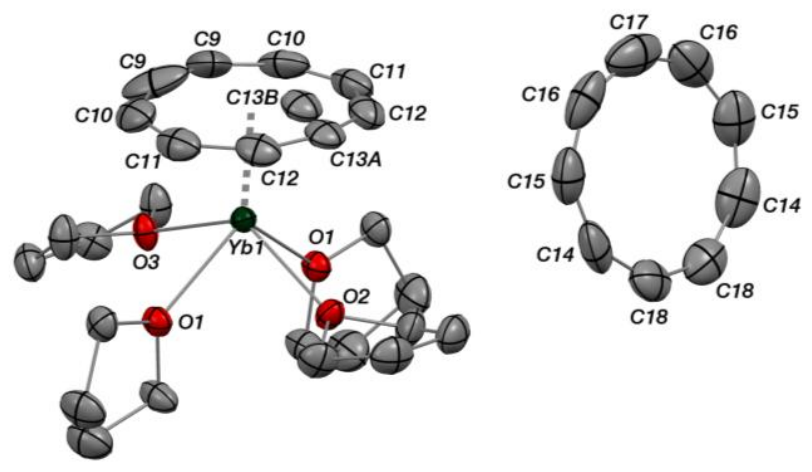

Figure 2. Molecular structure of 3 recorded at $150 \mathrm{~K}$; thermal ellipsoids are shown at $50 \%$ probability and the hydrogen atoms are omitted for clarity.

The dissolution of $\mathbf{1}$ in acetonitrile immediately leads to a color change from green to orange while the ${ }^{1} \mathrm{H}$ NMR spectrum shows only one resonance at $6.91 \mathrm{ppm}$ (Figure S6). A titration with small amounts of acetonitrile in dichloromethane solutions of $\mathbf{1}$ and $\mathbf{2}$ allows following the fast isomerization (Figure S17, Figure S19). Orange crystals can be obtained from a 1:10 room temperature acetonitrile/toluene solution of 1. They were analyzed as the ion-pair $\left[\mathrm{Yb}\left(\mathrm{CH}_{3} \mathrm{CN}\right)_{7}\right]\left[\mathbf{L}_{\mathbf{1}}\right]_{2}(\mathbf{4})$ (Figure 3). Two independent molecules are present in the unit cell and all ligands are cis. The geometry around both ytterbium metal centers is a distorted pentagonal bipyramid and the average Yb-N distances of 2.52(3) $\AA$ (Figure $2 \mathrm{~b}$ and S10) are also in agreement with a divalent center. However, the hepta- coordination in 4 slightly reduces the average $\mathrm{Yb}-\mathrm{N}$ distance compared to that of the octa-coordinated acetonitrile complex. $^{43}$ The key experiment is to expose the crystals of $\mathbf{4}$ under reduced pressure: after $8 \mathrm{~h}$ under $10^{-3}$ mbar vacuum, the yellow powder that is obtained does not contain any trace of acetonitrile and the sharp singlet resonance agrees with the presence of $\mathbf{1}^{\mathrm{cc}}$ as a unique isomer. ${ }^{26}$

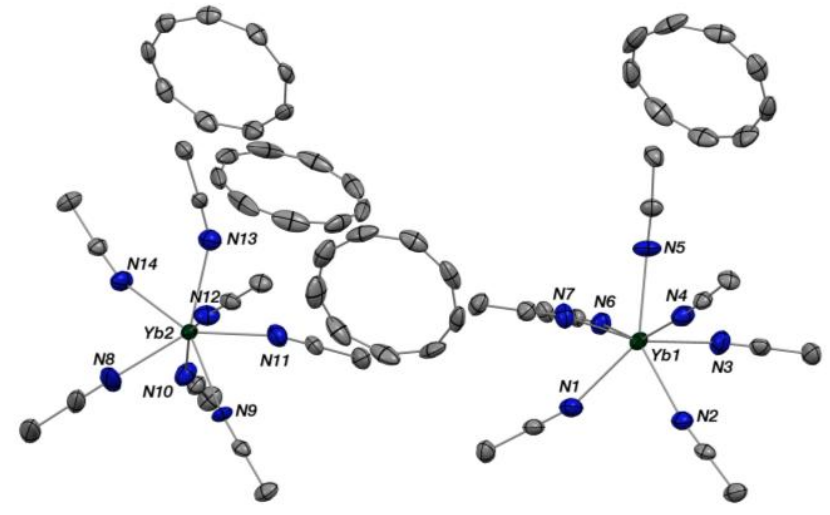

Figure 3. Molecular structure of 4 recorded at $150 \mathrm{~K}$; thermal ellipsoids are shown at $50 \%$ probability and the hydrogen atoms are omitted for clarity.

The UV-visible spectra of $\mathbf{1}^{c c}$ and $\mathbf{2}^{c c}$ were compared with those of 1 and 2 in which the Cnt ligand is not entirely isomerized. As expected from the less pronounced color of the symmetrical species, the extinction coefficient is larger in $\mathbf{1}$ and $\mathbf{2}$ while the bands' energies are very similar. The light yellow and orange colors of $\mathbf{1}^{c c}$ and $\mathbf{2}^{c c}$, respectively correspond to a low intense tail from $400 \mathrm{~nm}$ to $700 \mathrm{~nm}$ (Figure S20-S21).
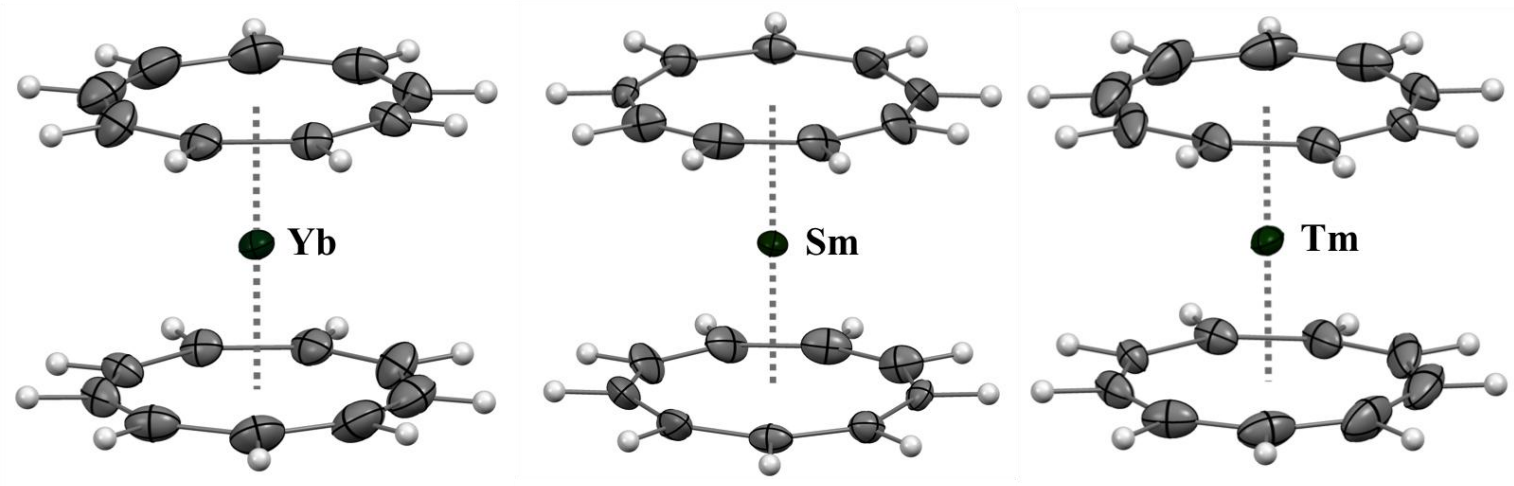

Figure 4. Molecular structure of $\mathbf{1}^{\mathbf{c c}}, \mathbf{2}^{\mathrm{cc}}$ and $\mathbf{6}^{\mathrm{cc}}$ recorded at $150 \mathrm{~K}$; thermal ellipsoids are shown at $50 \%$ probability. Disordered carbon atoms are not shown for clarity.

Table 1. Main metric parameters $\mathbf{1}^{\mathbf{c c}}, \mathbf{2}^{\mathbf{c c}}, \mathbf{5}^{\mathbf{c c}}$, and $\mathbf{6}^{\mathbf{c c}}$. Distances are given in $\AA$ and angles in deg, ctr is for centroid.

\begin{tabular}{ccccc}
\hline & $\mathbf{1}$ & $\mathbf{2}$ & $\mathbf{5}$ from ref $^{\mathbf{3 8}}$ & $\mathbf{6}$ \\
\hline \multirow{2}{*}{$\mathrm{C}-\mathrm{C}$ range in ring } & $1.33(3)-$ & $1.33(1)-1.47(2)$ & $1.353(15)-1.448(13)$ & $1.32(1)-1.47(2)$ \\
\hline
\end{tabular}




\begin{tabular}{lllll}
\hline Average C-C & $1.39(4)$ & $1.39(4)$ & $1.39(2)$ & $1.39(4)$ \\
M-C(N) range & $2.74(2)-$ & $2.833(8)-$ & $2.796(13)-2.957$ & $2.736(8)-2.760(8)$ \\
M-C(N) average & $2.86(2)$ & $2.958(6)$ & & $2.75(1)$ \\
M- $\mathrm{L}_{1}(\mathrm{ctr})$ & $2.79(3)$ & $2.88(3)$ & $2.87(4)$ & 1.91 \\
ctr-ctr & 1.932 & 2.061 & 2.065 & 3.82 \\
Ring size (max C' C- & 3.865 & 4.122 & 4.131 & 4.02 \\
C) & 4.06 & 4.05 & 4.02 & 180 \\
ctr-Ln-ctr & 180 & 180 & 180 & \\
\hline
\end{tabular}

Complexes $1^{c c}$ and $2^{c c}$ are only sparingly soluble in toluene and benzene but are soluble and stable in dichloromethane. The stability in dichloromethane is rather abnormal for divalent $\mathrm{Sm}$ and $\mathrm{Yb}^{44}$ However, this unexpected stability may open new perspectives in the study of their coordination chemistry and reactivity. With a new synthetic procedure in hand, we also performed the synthesis of the europium analogue $\mathrm{Eu}\left(\mathbf{L}_{\mathbf{1}}\right)_{2}(\mathbf{5})$ in good yield $(62 \%)^{38}$ and more perilously that of the "non-classical" and very reducing divalent lanthanide thulium, ${ }^{45-46} \operatorname{Tm}\left(\mathbf{L}_{\mathbf{1}}\right)_{2}$ (6) (33 \%), starting from $\mathrm{TmI}_{2}(\mathrm{thf})_{3 \cdot}{ }^{47}$ All compounds $\mathbf{1}^{\text {ce }}, \mathbf{2}^{\text {ce }}, \mathbf{5}^{\text {cc }}$, and $\mathbf{6}^{\text {cc }}$ are isomorphous and isostructural (Figure 4).

The sandwich complexes $\mathbf{1}^{\mathbf{c c}}, \mathbf{2}^{\mathbf{c c}}, \mathbf{5}^{\mathrm{cc}}$, and $\mathbf{6}^{\mathrm{cc}}$ crystallize in the $\mathrm{P} 2_{1} / \mathrm{n}$ space group. The $\mathrm{Cnt}$ rings are disordered so that there is an alternation of stacked, $\mathrm{D}_{9 \mathrm{~h}}$ and eclipsed $\mathrm{D}_{9 \mathrm{~d}}$ symmetry. Interestingly the ring size, measured with the maximal through-space C...C-C distance, is close to that of the centroid-centroid distance. The resulting high symmetry is likely to induce interesting spectroscopic properties. ${ }^{38}$ The Ln-C and Ln-ctr distances (Table S9) compare similarly with Ln-Cot distances; ${ }^{21-22,}{ }^{48} 1.932 \AA$ in $1,2.061 \AA$ in $2,2.065 \AA$ in $5,{ }^{34}$ and $1.910 \AA$ in 6 , following the lanthanide contraction trend (Table 1), while they are shorter than that of Ln-Cp typical distances. ${ }^{49}$ The centroid-Ln-centroid angle is of $180^{\circ}$, in agreement with rigorously linear sandwich compounds. The sandwich compounds pack in the solid-state without obvious intermolecular interactions (Figure S32), the shortest carboncarbon contact being $3.715 \AA$ for $\mathbf{1}^{\mathbf{c c}}, 3.694 \AA$ for $\mathbf{2}^{\mathbf{c c}}$ and $3.711 \AA$ for $6^{\mathrm{cc}}$. All compounds are air-sensitive although the sandwich complexes are relatively more stable than the thf half-sandwich adduct, $\mathbf{3}$, or the heptaacetonitrile complex, $\mathbf{4}$.

Bonding Analysis. The structures of the sandwich complexes were optimized in the gas phase using DFT and a qualitative molecular orbital diagram for $\mathbf{1}^{c c}$ is given in $\mathrm{D}_{9 \mathrm{~d}}$ symmetry (Figure 5). The $(\mathrm{Cnt})_{2}$ fragments have several symmetryadapted orbitals mixing with 4 f-orbitals: $1_{\mathrm{e} 2 \mathrm{u}}$ and $2_{\mathrm{e} 2 \mathrm{u}}$ are the bonding and anti-bonding combination of the ligands $\mathrm{E}_{2 \mathrm{u}}$ orbitals with the $\mathrm{f}-\delta$ orbitals and $1_{\mathrm{e} 3 \mathrm{u}}$ is the bonding combination of the ligands $E_{3 u}$ orbitals with the $f-\phi$ orbitals, similarly to the uranocene and cerocene. ${ }^{10,17}$ The other f-orbitals do not combine with the ligand. For the ytterbocene and europocene (filled and half-filled 4f-shell) the relative energy and symmetry of the Kohn-Sham highest occupied orbitals (Figure 6) fit very well with the qualitative molecular orbital diagram. The population analysis for all complexes (Tables S1-S3) is of 91 to $96 \% 4 \mathrm{f}$ and 4 to $8 \% \mathrm{Cnt}$ in $1_{\mathrm{e} 3 \mathrm{u}}$ and $2_{\mathrm{e} 2 u}$, while it is of 91 and $93 \% \mathrm{Cnt}$ and 5-8\% 4f in $1_{\mathrm{e} 2 \mathrm{u}}$ and $2_{\mathrm{e} 3 \mathrm{u}}$, in agreement with the expected predominantly ionic bonding.

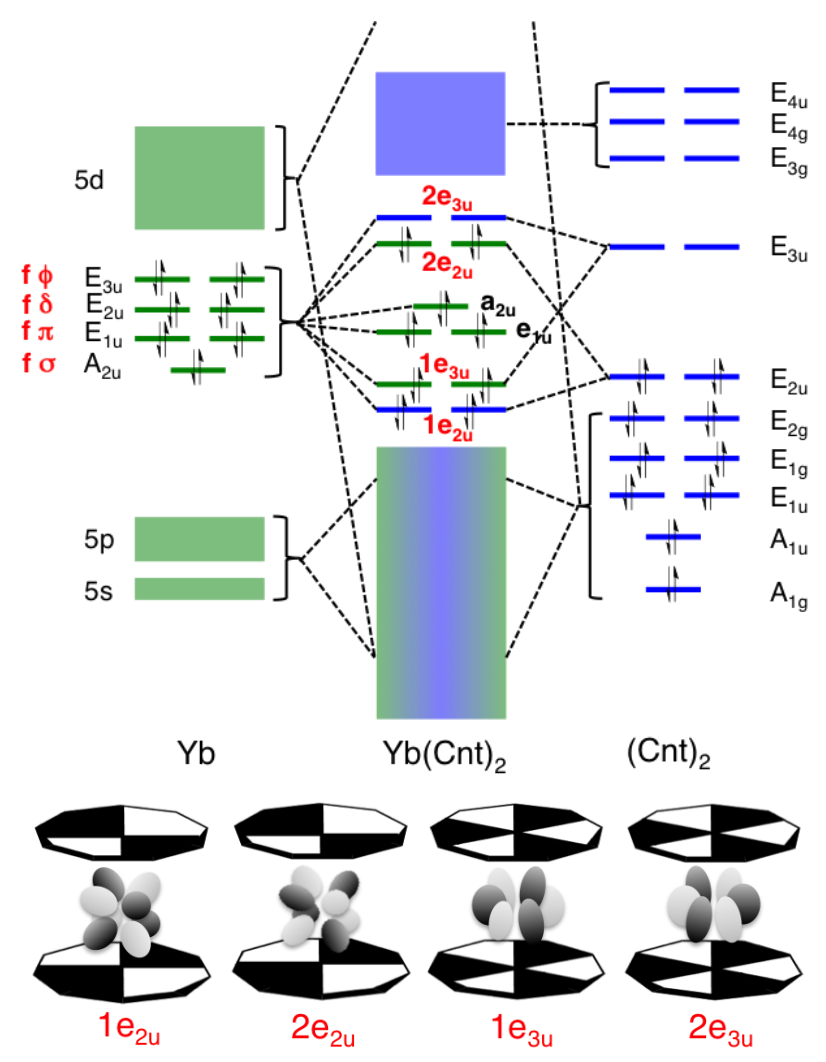

Figure 5. Molecular orbital diagram of $\mathrm{Yb}(\mathrm{Cnt})_{2}(\mathbf{1})$ in $\mathrm{D}_{9 \mathrm{~d}}$ symmetry (the blue color is for ligand-based orbitals, the green for metal-based orbitals) and principal molecular orbitals schematic picture.

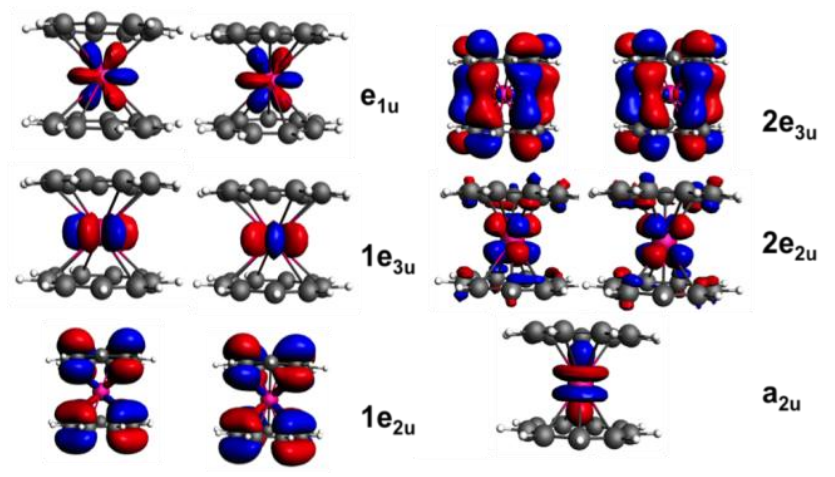

Figure 6. Kohn-Sham highest occupied molecular and LUMO $\left(2 \mathrm{e}_{3 \mathrm{u}}\right)$ orbitals of $\mathrm{Yb}(\mathrm{Cnt})_{2}(\mathbf{1})$.

\section{CONCLUSIONS.}


This work describes the original synthesis, the structure, and bonding of four lanthanidocenes, linear sandwich compounds with the Cnt ligand. The easy access to these compounds in appreciable yields closes the gap between the transition metals metallocenes with the Cp ligand, such as ferrocene, and tetravalent $4 \mathrm{f}-$ and $5 \mathrm{f}$ metallocenes with the Cot ligand, such as uranocene and cerocene. The molecular structures feature two $\eta^{9}$-coordinated ligands in a rigorously linear sandwich arrangement. Their simple nature and original symmetry will naturally engage a series of further structural, spectroscopic and theoretical studies along the lanthanide series. Additionally, the formation of a very rare base-free thulium complex, as well as the absence of reactivity with dichloromethane advantageously enlarges the scope of what can be done with very reactive divalent lanthanides compounds. Additionally, the coordination dynamics of the Cnt ligand will also favor rich coordination chemistry and related reactivity.

\section{EXPERIMENTAL SECTION.}

General Procedures. All reactions were performed using standard Schlenk-line techniques or in argon or nitrogen filled gloveboxes (MBraun). All glassware was dried at $140^{\circ} \mathrm{C}$ for at least $12 \mathrm{~h}$ prior to use. Thf, diethylether, toluene, $\mathrm{CD}_{3} \mathrm{CN}, \mathrm{C}_{6} \mathrm{D}_{6}$ and toluene- $\mathrm{d}_{8}$ were dried over sodium (or $\mathrm{CaH}_{2}$ for $\mathrm{CD}_{3} \mathrm{CN}$ ), degassed and transferred under reduced pressure in a cold flask. $\mathrm{YbI}_{2}$ and $\mathrm{SmI}_{2}$ were prepared following literature procedures ${ }^{44,50}$ while $\mathrm{EuI}_{2}$ and $\mathrm{TmI}_{2}$ were purchased from Aldrich. NMR spectra were recorded in $5 \mathrm{~mm}$ tube adapted with a J. Young valve on Bruker $300 \mathrm{MHz}$ Avance III spectrometers. Chemical shifts are expressed relative to TMS in ppm.

Syntheses. Preparation of potassium cyclononatetraenyl (KCnt). The potassium cyclononatetraenyl salt was prepared following a modified literature procedure. ${ }^{37,}$ 40 9methoxybicyclo[6.1.0]nonatriene was diluted in $30 \mathrm{~mL}$ of thf before being added to potassium chunks suspended in $400 \mathrm{~mL}$ of thf cooled to $-40^{\circ} \mathrm{C}$ and let under stirring overnight. The brown slurry was then filtered and the solvents removed under reduced pressure to yield a brown solid, which was washed with pentane until the pentane fractions were colorless. Finally the solid was extracted with $\mathrm{Et}_{2} \mathrm{O}$ and the obtained solution was cooled to $-35^{\circ} \mathrm{C}$ to yield colorless blocks of $\left(\mathrm{Et}_{2} \mathrm{O}\right)_{2} \cdot \mathrm{KCnt}$ suitable for X-Ray diffraction. Since these crystals can easily lose their coordinated ether molecule, a great care should be taken while drying them under reduced pressure overnight before using them in order to make sure that no $\mathrm{Et}_{2} \mathrm{O}$ molecules are remaining in the ligand salt. ${ }^{1} \mathrm{H}$ NMR $\left(\mathrm{CD}_{3} \mathrm{CN}, 300 \mathrm{MHz}, \delta / \mathrm{ppm}\right): 7.15$ (dd, $J=15 \mathrm{~Hz}, 6 \mathrm{~Hz}, 2 \mathrm{H}), 6.94(\mathrm{~s}, 2.39 \mathrm{H}), 6.65(\mathrm{~m}, 4 \mathrm{H}), 6.49(\mathrm{~m}, 2 \mathrm{H}),-$ $3.54(\mathrm{t}, J=15 \mathrm{~Hz}, 1 \mathrm{H})$.

Preparation of bis(cyclononatetraenyl) ytterbium $\left(1^{c c}\right)$. To a solid mixture of KCnt (36.9 mg, $236 \mu \mathrm{mol}, 2$ eq.) and $\mathrm{YbI}_{2}(48.5 \mathrm{mg}, 113$ $\mu \mathrm{mol}, 1$ eq.) prepared in a Schlenk tube, $6 \mathrm{~mL}$ of toluene was added followed by 5 drops of thf. The tube was then cautiously protected with paraffin film and the obtained green slurry was stirred for two hours. After, the tube was depressurized and the mixture was stirred under static vacuum for a further $14 \mathrm{~h}$ before the white solid was filtered off and extracted with $8 \mathrm{~mL}$ of toluene (The static vacuum is helping to maximize the yield, decreasing the amount of thf in the solution while the reaction proceeds). The obtained deep green fractions were then gathered and concentrated before being cooled to $35^{\circ} \mathrm{C}$. The title product was then obtained as small black crystals (19.6 mg, $48.1 \mu \mathrm{mol}, 43 \%$ ) suitable for X-ray diffraction. The composition of the crystals can be evaluated by ${ }^{1} \mathrm{H}$ NMR, showing the presence of a mixture of $\mathbf{1}^{c c}, \mathbf{1}^{c t}$, and $\mathbf{1}^{t t}$. This ratio evolves with the timing of the reaction and work-up. The crystals can, be dissolved in a mixture 1:1 (v:v) of toluene and $\mathrm{MeCN}$ and stirred for $24 \mathrm{~h}$ before being evaporated and dried under reduced pressure to yield only the $\mathbf{1}^{\mathbf{c c}}$ isomer as a yellow powder which can be recrystallized if necessary from hot toluene as small yellow needles. ${ }^{1} \mathrm{H}$ NMR $\left(\mathrm{CD}_{2} \mathrm{Cl}_{2}, 300\right.$
$\mathrm{MHz}, \delta / \mathrm{ppm}):$ 7.16-7.03 (m), $7.16\left(\mathrm{~s}, \mathbf{1}^{c c}\right), 6.69-6.64(\mathrm{t}), 6.56-6.31$ $(\mathrm{m}),-3.97\left(\mathrm{t}, J=14.8 \mathrm{~Hz}, \mathbf{1}^{\mathrm{ct}}\right),-4.13\left(\mathrm{t}, J=14.8 \mathrm{~Hz}, \mathbf{1}^{t t}\right) .{ }^{13} \mathrm{C}\left\{{ }^{1} \mathrm{H}\right\}$ NMR $\left(\mathrm{CD}_{2} \mathrm{Cl}_{2}, 75.4 \mathrm{MHz}, \delta / \mathrm{ppm}\right): 127.00\left(\mathrm{~d}, J_{\mathrm{CH}}=126 \mathrm{~Hz}, \mathbf{1}^{t}\right)$, $121.83\left(\mathrm{~d}, J_{\mathrm{CH}}=162 \mathrm{~Hz}\right), 116.39\left(\mathrm{~d}, J_{\mathrm{CH}}=156 \mathrm{~Hz}\right), 111.12\left(\mathrm{~d}, J_{\mathrm{CH}}=\right.$ $154 \mathrm{~Hz}), 108.97\left(\mathrm{~d}, J_{\mathrm{CH}}=156 \mathrm{~Hz}\right), 108.40\left(\mathrm{~d}, J_{\mathrm{CH}}=157 \mathrm{~Hz}, \mathbf{1}^{c}\right)$. Elemental analysis: Calcd. for $\mathrm{C}_{18} \mathrm{H}_{18} \mathrm{Yb}$ : C, 53.09; H, 4.42. Found: C, 52.34; H, 4.44 .

Preparation of bis(cyclononatetraenyl) samarium $\left(2^{c c}\right)$. To a solid mixture of KCnt (44.0 mg, $281 \mu \mathrm{mol}, 2$ eq.) and $\mathrm{SmI}_{2}(54.3 \mathrm{mg}, 134$ $\mu \mathrm{mol}, 1$ eq.) prepared in a Schlenk tube, $6 \mathrm{~mL}$ of toluene was added followed by 5 drops of thf. The tube was cautiously protected with paraffin film and the obtained black slurry was stirred for two hours. After, the tube was depressurized and the mixture was stirred under static vacuum for a further $14 \mathrm{~h}$ before the white solid was filtered off and extracted with $8 \mathrm{~mL}$ of toluene. The obtained deep brown fractions were then gathered and concentrated before being cooled to $35^{\circ} \mathrm{C}$. The title product was then obtained as small black crystals $(28.8 \mathrm{mg}, 74.9 \mu \mathrm{mol}, 56 \%)$ suitable for X-ray diffraction. The composition of the crystals can be evaluated by ${ }^{1} \mathrm{H}$ NMR, showing the presence of a mixture of $\mathbf{2}^{c c}, \mathbf{2}^{c t}$, and $\mathbf{2}^{t t}$. This ratio evolves with the timing of the reaction and work-up. The crystals can be dissolved in a mixture 1:1 (v:v) of toluene and $\mathrm{MeCN}$ and stirred for $24 \mathrm{~h}$ before being evaporated and dried under reduced pressure to yield only the $2^{\mathbf{c c}}$ isomer as an orange powder which can be recrystallized if necessary from hot toluene as small orange needles. ${ }^{1} \mathrm{H}$ NMR (toluene- $\mathrm{d}_{8}$, $300 \mathrm{MHz}, \delta / \mathrm{ppm}): 50.30\left(\mathrm{~s}, \mathbf{2}^{t t}\right), 50.28\left(\mathrm{~s}, \mathbf{2}^{\mathrm{ct}}\right), 26.27\left(\mathrm{~s}, \mathbf{2}^{t t}\right), 23.03(\mathrm{~m}$, $\left.\mathbf{2}^{c t}\right), 22.89\left(\mathrm{~s}, \mathbf{2}^{c t}\right), 21.1\left(\mathrm{~m}, \mathbf{2}^{t t}\right), 20.67\left(\mathrm{~s}, \mathbf{2}^{c c}\right), 20.01\left(\mathrm{~m}, \mathbf{2}^{c t}\right), 15.27(\mathrm{~s}$, $\left.\mathbf{2}^{t t}\right), 6.00\left(\mathrm{~s}, \mathbf{2}^{c t}\right),-1.12\left(\mathrm{t}, \mathbf{2}^{t t}\right),-2.30\left(\mathrm{t}, \mathbf{2}^{c t}\right)$. The ${ }^{13} \mathrm{C}$ NMR spectrum was not satisfactory due to too pronounced paramagnetism. Elemental analysis: Calcd. for $\mathrm{C}_{18} \mathrm{H}_{18} \mathrm{Sm}$ : C, 56.22; H, 4.68. Found: $\mathrm{C}$, $55.86 ; \mathrm{H}, 4.87$.

Preparation of bis(cyclononatetraenyl) europium $\left(5^{c c}\right)$. To a solid mixture of KCnt (34.4 mg, $220 \mu \mathrm{mol}, 2$ eq.) and $\mathrm{EuI}_{2}$ (54.3 mg, 134 $\mu \mathrm{mol}, 1$ eq.) prepared in a Schlenk tube, $6 \mathrm{~mL}$ of toluene was added followed by 5 drops of the. The tube was cautiously protected with paraffin film and the obtained red slurry was stirred for two hours. After, the tube was depressurized and the mixture was stirred under static vacuum for a further $14 \mathrm{~h}$ before the solid was filtered off and extracted with $8 \mathrm{~mL}$ of toluene. The obtained red fractions were then gathered and concentrated before being cooled to $-35^{\circ} \mathrm{C}$. The title product was then obtained as small black crystals $(26.5 \mathrm{mg}, 68.6$ $\mu \mathrm{mol}, 62 \%$ ) suitable for X-ray diffraction. Because of the highly paramagnetic behavior of $\mathbf{5}$, the composition of the crystals could not be evaluated by ${ }^{1} \mathrm{H}$ NMR. The crystals have nevertheless been dissolved in a mixture 1:1 (v:v) of toluene and $\mathrm{MeCN}$ and stirred for 24 $\mathrm{h}$ before being evaporated and dried under reduced pressure to yield only the $\mathbf{5}^{\mathbf{c c}}$ isomer as a light orange powder, which can be recrystallized if necessary from hot toluene as small orange needles. The structure was similar to that already reported by Nakajima. ${ }^{38}$

Preparation of bis(cyclononatetraenyl) thulium $\left(6^{c c}\right)$. To a solid mixture of KCnt (12.1 mg, $77.6 \mu \mathrm{mol}, 2$ eq.) and $\mathrm{TmI}_{2}(\mathrm{thf})_{3}(24.8$ $\mathrm{mg}, 38.8 \mu \mathrm{mol}, 1$ eq.) prepared in a Schlenk tube $8 \mathrm{~mL}$ of toluene was added. The tube was cautiously protected with paraffin film and the obtained red slurry stirred for two hours at room temperature. The tube was then depressurized and the mixture was stirred under static vacuum for a further $14 \mathrm{~h}$ before the brown solid was filtered off and extracted with $8 \mathrm{~mL}$ of toluene. The obtained orange fractions were then gathered and concentrated before being cooled to $-35^{\circ} \mathrm{C}$. The title product was then obtained as a micro-crystalline purple-red powder (5.2 mg, $12.9 \mu \mathrm{mol}, 33 \%)$. X-Ray suitable deep red crystals can be obtained from the recrystallization of this powder from toluene. The ${ }^{1} \mathrm{H}$ NMR in toluene- $\mathrm{d}_{8}, 300 \mathrm{MHz}$ remains silent. Due to the relative thermal stability of $\mathbf{6}^{\text {cc }}$, the elemental analysis was not tried.

Isomerization of $\operatorname{Ln}(\mathrm{Cnt})_{2}$ induced by addition of $\mathrm{MeCN}$. To 0.5 $\mathrm{mL}$ of a saturated solution of $\mathrm{Ln}(\mathrm{Cnt})_{2}$ in $\mathrm{C}_{6} \mathrm{D}_{6}$ (for $\mathbf{1}$ ) or in tol- $\mathrm{d}_{8}$ (for 2) was added $0.1 \mathrm{~mL}$ of $\mathrm{CD}_{3} \mathrm{CN}$. A color shift was immediately observed. The reaction was then monitored by ${ }^{1} \mathrm{H}$ NMR. When only 
one isomer was remaining in solution, solvents were removed under reduced pressure yielding a yellow solid (for 1) or an orange solid (for 2) which was re-dissolved in hot $\mathrm{C}_{6} \mathrm{D}_{6}$ and ${ }^{1} \mathrm{H}$ NMR spectroscopy was performed on the sample.

Theoretical calculations. Geometry optimizations were performed without any symmetry constraints using the scalar relativistic ZORA Hamiltonian at the DFT level with Orca program package. ${ }^{51}$ The SARC-TZVP adapted basis sets were used. The structures were checked to correspond to energy minima by calculating frequencies at the optimized geometries. Several functionals were used, i.e. PBE, PBE0, SSB-D, TPSSH and were associated to dispersion corrections in the framework proposed by Grimme.$^{52}$ The electronic structure has been found to be qualitatively non-functional dependent. DFT Calculations were performed both in the gas phase and in toluene using the CPCM method but solvent effects did not change the global picture. Consequently, the detailed analyses, in the $\mathrm{D}_{3 \mathrm{~d}}$ symmetry, described here were obtained at the SSB-D/TZ2P level based on TPSSH optimized geometries, using the ADF program package. ${ }^{53}$

$\mathbf{X}$-ray crystal structures. The structure resolution was accomplished using the SHELXS- $97^{54}$ and SHELXT ${ }^{55}$ program and the refinement was done with the SHELXL ${ }^{56}$ program. The structure solution and the refinement were achieved with the PLATON software ${ }^{57}$ Finally, pictures of the compound structure were obtained using the MERCURY software. During the refinement steps, all atoms- except hydrogen atoms- were refined anisotropically. The position of the hydrogen atoms was determined using residual electronic densities. Finally, in order to obtain a complete refinement, a weighting step followed by multiples loops of refinement was done. The crystal structures of $\mathrm{KL}_{\mathbf{1}} \cdot \mathrm{OEt}_{2}, \mathbf{1 - 4}$, and $\mathbf{6}$ have been deposited in the CCDC with \#1861445-1861450.

\section{ASSOCIATED CONTENT}

\section{Supporting Information}

Additional information on the syntheses, solution NMR data, UV-visible spectroscopy, computations and structural information are given in the supporting information. The Supporting Information is available free of charge on the ACS Publications website.

\section{AUTHOR INFORMATION}

\section{Corresponding Author \\ * greg.nocton@polytechnique.edu}

\section{Funding Sources}

Parts of this project have received funding from the French National Agency with grant number ANR-15-CE29-0019. This work was performed using HPC resources from GENCI[CINES/IDRIS] (Grant 2017- [A0040806830]).

\section{ACKNOWLEDGMENT}

MX is grateful to the DGA. CNRS and Ecole polytechnique are thanked for funding. Prof. Marc Walter and Prof. Richard A. Andersen are thanked for helpful discussions, and Dr. Jules Moutet for help in the preparation of the manuscript.

\section{REFERENCES}

1. Kealy, T. J.; Pauson, P. L., A New Type of Organo-Iron Compound. Nature 1951, 168, 1039.

2. Wilkinson, G.; Rosenblum, M.; Whiting, M. C.; Woodward, R. B., THE STRUCTURE OF IRON BISCYCLOPENTADIENYL. J. Am. Chem. Soc. 1952, 74, 2125-2126.

3. Fischer, E. O.; Pfab, W., Cyclopentadien-Metallkomplexe, ein neuer Typ metallorganischer Verbindungen. In Z. Naturforsch. B, 1952; Vol. 7, p 377.
4. Metallocenes: Synthesis Reactivity Applications. Togni, A.,

Halternan, R. L., Eds.; WILEY-VCH Verlag GmbH: Weinheim, Germany, 1998

5. Morrison, C. A.; Wright, D. S.; Layfield, R. A., Interpreting Molecular Crystal Disorder in Plumbocene, $\mathrm{Pb}(\mathrm{C} 5 \mathrm{H} 5) 2$ : Insight from Theory. J. Am. Chem. Soc. 2002, 124, 6775-6780.

6. Jutzi, P.; Burford, N., Main Group Metallocenes. In Metallocenes: Synthesis Reactivity Applications, Togni, A.;

Halterman, R. L., Eds. WILEY-VCH Verlag GmbH: Weinheim, Germany, 1998.

7. Wilkinson, G.; Birminham, J. M., CYCLOPENTADIENYL COMPOUNDS OF SC, Y, LA, CE AND SOME LANTHANIDE ELEMENTS. J. Am. Chem. Soc. 1954, 76, 6210-6210.

8. Birmingham, J. M.; Wilkinson, G., THE CYCLOPENTADIENIDES OF SCANDIUM, YTTRIUM AND SOME RARE EARTH ELEMENTS. J. Am. Chem. Soc. 1956, 78 , $42-44$.

9. Reynolds, L. T.; Wilkinson, G., $\pi$-cyclopentadienyl compounds of uranium-IV and thorium-IV. J. Inorg. Nucl. Chem. 1956, 2, 246-253.

10. Streitwieser, A.; Mueller-Westerhoff, U., Bis(cyclooctatetraenyl)uranium (uranocene). A new class of sandwich complexes that utilize atomic f orbitals. J. Am. Chem. Soc. 1968, $90,7364-7364$.

11. Zalkin, A.; Raymond, K. N., Structure of di-.pi.cyclooctatetraeneuranium (uranocene). J. Am. Chem. Soc. 1969, 91, 5667-5668.

12. Greco, A.; Cesca, S.; Bertolini, W., New 7rcyclooctate'I'raenyl and iT-cyclopentadienyl complexes of cerium. $J$. Organomet. Chem. 1976, 113, 321-330.

13. Dolg, M.; Fulde, P.; Kuchle, W.; Neumann, C. S.; Stoll, H., Ground-State Calculations of Di-Pi-Cyclooctatetraene Cerium. $J$. Chem. Phys. 1991, 94, 3011-3017.

14. Mooßen, O.; Dolg, M., Two interpretations of the cerocene electronic ground state. Chem. Phys. Lett. 2014, 594, 47-50.

15. Walter, M. D.; Booth, C. H.; Lukens, W. W.; Andersen, R. A., Cerocene Revisited: The Electronic Structure of and Interconversion Between $\mathrm{Ce}-2(\mathrm{C} 8 \mathrm{H} 8)(3)$ and $\mathrm{Ce}(\mathrm{C} 8 \mathrm{H} 8)(2)$. Organometallics 2009, 28, 698-707.

16. Kerridge, A.; Coates, R.; Kaltsoyannis, N., Is Cerocene Really a Ce(III) Compound? All-Electron Spin-Orbit Coupled CASPT2 Calculations on $\mathrm{M}(\eta 8-\mathrm{C} 8 \mathrm{H} 8) 2(\mathrm{M}=\mathrm{Th}, \mathrm{Pa}, \mathrm{Ce}) . J$. Phys. Chem. A 2009, 113, 2896-2905.

17. Kerridge, A., Oxidation state and covalency in f-element metallocenes $(\mathrm{M}=\mathrm{Ce}, \mathrm{Th}, \mathrm{Pu})$ : a combined CASSCF and topological study. Dalton Trans. 2013, 42, 16428-16436.

18. O., F. E.; H., F., Dicyclopentadienyleuropium. Angew. Chem. Int. Ed. Engl. 1964, 3, 132-133.

19. Fischer, E. O.; Fischer, H., UBER DICYCLOPENTADIENYLEUROPIUM UND DICYCLOPENTADIENYLYTTERBIUM UND TRICYCLOPENTADIENYLE DES TERBIUMS HOLMIUMS THULIUMS UND LUTETIUMS. J. Organomet. Chem. 1965, 3 , 181.

20. Hodgson, K. O.; Mares, F.; Starks, D. F.; Streitwieser, A., Lanthanide(III) complexes with cyclooctatetraene dianion. Synthetic chemistry, characterization, and physical properties. J. Am. Chem. Soc. 1973, 95, 8650-8658.

21. Le Roy, J. J.; Ungur, L.; Korobkov, I.; Chibotaru, L. F.; Murugesu, M., Coupling Strategies to Enhance Single-Molecule Magnet Properties of Erbium-Cyclooctatetraenyl Complexes. J. Am. Chem. Soc. 2014, 136, 8003-8010.

22. Meihaus, K. R.; Long, J. R., Magnetic Blocking at $10 \mathrm{~K}$ and a Dipolar-Mediated Avalanche in Salts of the Bis( $\eta 8$ cyclooctatetraenide) Complex $[\operatorname{Er}(\mathrm{COT}) 2]-$. J. Am. Chem. Soc. 2013, $135,17952-17957$.

23. Anderson, D. M.; Cloke, F. G. N.; Cox, P. A.; Edelstein, N.; Green, J. C.; Pang, T.; Sameh, A. A.; Shalimoff, G., On the 
stability and bonding in bis( $\eta$-arene)ianthanide complexes. J. Chem. Soc., Chem. Commun. 1989, 53-55.

24. Brennan, J. G.; Cloke, F. G. N.; Sameh, A. A.; Zalkin, A., Synthesis of bis( $\eta$-1,3,5-tri-t-butylbenzene) sandwich complexes of yttrium(0) and gadolinium( $(0)$; the X-ray crystal structure of the first authentic lanthanide(0) complex, [Gd( $\eta$-But3C6H3)2]. J. Chem. Soc., Chem. Commun. 1987, 1668-1669.

25. Helmut, S.; Thomas, D.; Oliver, S.; Frank, W.; Gotthelf, W.; Michael, R., Metallocenes of Samarium, Europium, and Ytterbium with the Especially Bulky Cyclopentadienyl Ligands $\mathrm{C} 5 \mathrm{H}(\mathrm{CHMe} 2) 4$, C5H2(CMe3)3, and $\mathrm{C} 5(\mathrm{CHMe} 2) 5$. Z. Anorg. Allg. Chem. 2000, 626, 2241-2244.

26. Deacon, G. B.; Forsyth, C. M.; Jaroschik, F.; Junk, P. C.; Kay, D. L.; Maschmeyer, T.; Masters, A. F.; Wang, J.; Field, L. D., Accessing Decaphenylmetallocenes of Ytterbium, Calcium, and Barium by Desolvation of Solvent-Separated Ion Pairs: Overcoming Adverse Solubility Properties. Organometallics 2008, 27 , 47724778 .

27. Kelly, R. P.; Bell, T. D. M.; Cox, R. P.; Daniels, D. P.; Deacon, G. B.; Jaroschik, F.; Junk, P. C.; Le Goff, X. F.; Lemercier, G.; Martinez, A.; Wang, J.; Werner, D., Divalent Tetra- and Pentaphenylcyclopentadienyl Europium and Samarium Sandwich and Half-Sandwich Complexes: Synthesis, Characterization, and Remarkable Luminescence Properties. Organometallics 2015, 34 , 5624-5636.

28. Goodwin, C. A. P.; Reta, D.; Ortu, F.; Chilton, N. F.; Mills, D. P., Synthesis and Electronic Structures of Heavy Lanthanide Metallocenium Cations. J. Am. Chem. Soc. 2017, 139, 18714-18724.

29. Goodwin, C. A. P.; Ortu, F.; Reta, D.; Chilton, N. F.; Mills, D. P., Molecular magnetic hysteresis at 60 kelvin in dysprosocenium. Nature 2017, 548, 439.

30. Guo, F.-S.; Day, B. M.; Chen, Y.-C.; Tong, M.-L.; Mansikkamäki, A.; Layfield, R. A., A Dysprosium Metallocene Single-Molecule Magnet Functioning at the Axial Limit. Angew. Chem. Int. Ed. 2017, 56, 11445-11449.

31. Day, B. M.; Guo, F.-S.; Layfield, R. A., Cyclopentadienyl Ligands in Lanthanide Single-Molecule Magnets: One Ring To Rule Them All? Acc. Chem. Res. 2018, 51, 1880-1889.

32. Ruspic, C.; Moss, J. R.; Schürmann, M.; Harder, S., Remarkable Stability of Metallocenes with Superbulky Ligands: Spontaneous Reduction of SmIII to SmII. Angew. Chem. Int. Ed. 2008, $47,2121-2126$.

33. Harder, S.; Naglav, D.; Ruspic, C.; Wickleder, C.; Adlung, M.; Hermes, W.; Eul, M.; Pöttgen, R.; Rego, D. B.; Poineau, F.; Czerwinski, K. R.; Herber, R. H.; Nowik, I., Physical Properties of Superbulky Lanthanide Metallocenes: Synthesis and Extraordinary Luminescence of [EuII(CpBIG)2] (CpBIG=(4-nBu-C6H4)5Cyclopentadienyl). Chem. Eur. J. 2013, 19, 12272-12280.

34. Evans, W. J., Tutorial on the Role of Cyclopentadienyl Ligands in the Discovery of Molecular Complexes of the Rare-Earth and Actinide Metals in New Oxidation States. Organometallics 2016, $35,3088-3100$

35. Woen, D. H.; Evans, W. J., Chapter 293 - Expanding the +2 Oxidation State of the Rare-Earth Metals, Uranium, and Thorium in Molecular Complexes. In Handbook on the Physics and Chemistry of Rare Earths, Bünzli, J.-C. G.; Pecharsky, V. K., Eds. Elsevier: 2016; Vol. 50, pp 337-394.

36. Murahashi, T.; Inoue, R.; Usui, K.; Ogoshi, S., Square Tetrapalladium Sheet Sandwich Complexes: Cyclononatetraenyl as a Versatile Face-Capping Ligand. J. Am. Chem. Soc. 2009, 131, 98889889.

37. Katz, T. J.; Garratt, P. J., The Cyclononatetraenyl Anion. J. Am. Chem. Soc. 1963, 85, 2852-2853.

38. Kawasaki, K.; Sugiyama, R.; Tsuji, T.; Iwasa, T.; Tsunoyama, H.; Mizuhata, Y.; Tokitoh, N.; Nakajima, A., A designer ligand field for blue-green luminescence of organoeuropium(ii) sandwich complexes with cyclononatetraenyl ligands. Chem. Commun. 2017, 53, 6557-6560.

39. Walter, M. D.; Wolmershäuser, G.; Sitzmann, H., Calcium, Strontium, Barium, and Ytterbium Complexes with
Cyclooctatetraenyl or Cyclononatetraenyl Ligands1. J. Am. Chem. Soc. 2005, 127, 17494-17503.

40. Katz, T. J.; Garratt, P. J., Reactions of the Cyclooctatetraenyl Dianion with gem-Dihalides. The Preparation of Derivatives of Bicyclo [6.1.0]nonatriene. Synthesis of the Cyclononatetraenyl Anion. J. Am. Chem. Soc. 1964, 86, 5194-5202.

41. Gernot, B.; Andreas, B., Isomerisierung des cis,cis,cis,trans-[9]Annulen-Anions. Chem. Ber. 1978, 2850-2858.

42. Tilley, T. D.; Andersen, R. A.; Spencer, B.; Ruben, H.; Zalkin, A.; Templeton, D. H., DIVALENT LANTHANIDE CHEMISTRY

BIS(PENTAMETHYLCYCLOPENTADIENYL)EUROPIUM(II)

AND

BIS(PENTAMETHYCYCLOPENTADIENYL)YTTERBIUM(II) DERIVATIVES - $\quad$ CRYSTAL-STRUCTURE OF BIS(PENTAMETHYLCYCLOPENTADIENYL)(TETRAHYDROF URAN)YTTERBIUM(II)-HEMITOLUE NE AT 176-K. Inorg. Chem. 1980, 19, 2999-3003.

43. Evans, W. J.; Johnston, M. A.; Greci, M. A.; Gummersheimer, T. S.; Ziller, J. W., Divalent lanthanide complexes free of coordinating anions: facile synthesis of fully solvated dicationic [LnLx]2+ compounds. Polyhedron 2003, 22, 119-126.

44. Girard, P.; Namy, J. L.; Kagan, H. B., DIVALENT LANTHANIDE DERIVATIVES IN ORGANIC-SYNTHESIS .1. MILD PREPARATION OF SMI2 AND YBI2 AND THEIR USE AS REDUCING OR COUPLING AGENTS. J. Am. Chem. Soc. 1980, 102, 2693-2698.

45. Xémard, M.; Jaoul, A.; Cordier, M.; Molton, F.; Cador, O.; Le Guennic, B.; Duboc, C.; Maury, O.; Clavaguéra, C.; Nocton, G., Divalent Thulium Triflate: A Structural and Spectroscopic Study. Angew. Chem. Int. Ed. 2017, 56, 4266-4271.

46. Nief, F., Non-classical divalent lanthanide complexes. Dalton Trans. 2010, 39, 6589-6598.

47. Bochkarev, M. N.; Fedushkin, I. L.; Fagin, A. A.; Petrovskaya, T. V.; Ziller, J. W.; BroomhallDillard, R. N. R.; Evans, W. J., Synthesis and structure of the first molecular thulium(II) complex: [TmI2(MeOCH(2)CH(2)OMe)(3)]. Angew. Chem. Int. Ed. Engl. 1997, 36 , 133-135.

48. Kinsley, S. A.; Streitwieser, A.; Zalkin, A., Dipotassium bis([8]annulene)ytterbate(II) and -calcate(II). Organometallics $\mathbf{1 9 8 5}$, $4,52-57$.

49. Apostolidis, C.; B. Deacon, G.; Dornberger, E.; T. Edelmann, F.; Kanellakopulos, B.; MacKinnon, P.; Stalke, D., Crystallization and $\mathrm{X}$-ray structures of $[\mathrm{NaYb}(\mathrm{C} 5 \mathrm{H} 5) 3]$ and $\mathrm{Yb}(\mathrm{C} 5 \mathrm{H} 5) 2$. Chem. Commun. 1997, 1047-1048.

50. Tilley, T. D.; Boncella, J. M.; Berg, D. J.; Burns, C. J.; Andersen, R. A.; Lawless, G. A.; Edelman, M. A.; Lappert, M. F., Bis[Bis(Trimethylsilyl)Amido]Bis(Diethyl Ether)Ytterbium and

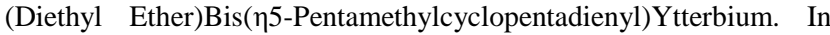
Inorganic Syntheses, Ginsberg, A. P., Ed. John Wiley \& Sons, Inc.: 2007; pp 146-150.

51. Neese, F., The ORCA program system. Wiley Interdiscip. Rev. Comput. Mol. Sci. 2012, 2, 73-78.

52. Grimme, S.; Antony, J.; Ehrlich, S.; Krieg, H., A consistent and accurate ab initio parametrization of density functional dispersion correction (DFT-D) for the 94 elements H-Pu. J. Chem. Phys. 2010, 132, 154104-19.

53. te Velde, G.; Bickelhaupt, F. M.; Baerends, E. J.; Fonseca Guerra, C.; van Gisbergen, S. J. A.; Snijders, J. G.; Ziegler, T., Chemistry with ADF. J. Computat. Chem. 2001, 22, 931-967.

54. Sheldrick, G. M., A short history of SHELX. Acto Crystallogr. A 2008, 64, 112-122.

55. Sheldrick, G., SHELXT - Integrated space-group and crystal-structure determination. Acta Crystallogr. A 2015, 71, 3-8.

56. Sheldrick, G., Crystal structure refinement with SHELXL. Acta Crystallogr. C 2015, 71, 3-8.

57. Spek, A., Single-crystal structure validation with the program PLATON. J. Appl. Crystallogr. 2003, 36, 7-13. 
